Research Journal of Applied Sciences 6 (4): 264-271, 2011

ISSN: $1815-932 \mathrm{X}$

(C) Medwell Journals, 2011

\title{
22 Years Characterized Trends of Rainfall in Abeokuta, Nigeria
}

\author{
${ }^{1}$ Nsikan I. Obot., ${ }^{2}$ Terhemba T. Emberga and ${ }^{3}$ Kehinde S. Ishola \\ ${ }^{1}$ Department of Science Lab Tech., Federal Polytecnic Ilaro, Ogun State, Nigeria \\ ${ }^{2}$ Department of Physics/Electronics, Federal Polytechnic Nekede, Imo State, Nigeria \\ ${ }^{3}$ Department of Geosciences, University of Lagos, Akoka, Lagos, Nigeria
}

\begin{abstract}
Many processes are dictated by rainfall so the knowledge of the trends of rainfall in the respective localities is very important amidst the concern of the effect of anthropogenic activities. To this end the rainfall trends in terms of cumulative total amount and total number of rain days in Abeokuta $\left(7^{\circ} 15^{\prime} \mathrm{N}, 3^{\circ} 35^{\prime} \mathrm{E}\right)$ Nigeria for 22 years (1981-2002) are investigated using the Mann-Kendall non parametric test. The results of the Mann-Kendall $Z$ test for both cumulative total rainfall amount and rainy days are 0.90 and 1.47 , respectively. The test values for dry season and raining season partitions of the same period for both parameters are 0.56 , 0.45 and $0.39,0.50$. All the results even with monthly evaluations at $90 \%$ confidence level indicate no significant trend and activities like farming can be carried out in accordance with established rainfall pattern without fear of change, though continues monitoring is advised to detect any possible U-turn. While the yearly cumulative rainfall seemingly does not depend on solar intensity, its seasonal variability is in tune with sun earth distance.
\end{abstract}

Key words: Abeokuta, rainfall, Mann-Kendall test, no significant trend, farming, Nigeria

\section{INTRODUCTION}

Rainfall is a determinant factor of many natural occurrences. Vegetation distributions and types over land masses are as a result of rainfall (Ronen and Avinoam, 1999; Tielborger and Kadmon, 2000; Shukla et al., 1990). Animals breeding periods synchronize with rainfall periods (Radford and Du Plessis, 2003). Rainfall events have been directly linked to sickness and diseases particularly those of waterborne and vector-borne types (Hunter, 2003). Crops planting, yields and harvests are influenced by rainfall and should be practiced in accordance with their respective enabling seasons to ensured improved productivity (Laux et al., 2010; Mudita et al., 2008; Omokhafe and Emuedo, 2006). The gaseous content of soil composition from time to time is much affected by rainfall (Lee et al., 2002). Investments in agricultural produces and products are expected to be done in accordance with knowledge of rainfall and other weather conditions (Morduch, 1995). And no matter how small the amount and duration of rainfall may be, it is economically significant to some species of plants under certain climate even so that it is hypothesized that the small events on the ecosystem dynamics are more effective than larger events (Sala and Lauenroth, 1982). Naturally, rainfall variability is of spatial and temporal forms and within these variations if by time series analysis no significant trend is obtained then the rainfall is steady otherwise it has changed. The steady state of rainfall over a reasonable length of time to some degree would ensure stability in the aforementioned systems. Contrarily it could lead to disruption, uncertainty and unpredictability of the systems.

With regards to rainfall, studies have pointed to the fact that the climate is changing (Goswami et al., 2006; Adger et al., 2003; Obot et al., 2010). Specifically, the research of Ragab and Prudhomme (2002) discusses the variability and uncertainty of rainfall across the whole globe amidst global warming and among others it states that while North Africa witnesses rainfall decrease, the regime of rainfall in some parts of South Africa is increasing. On the other hand, no coherent trend has been reported in some regions, in the face of different significant trends of other regions in Sri Lanka (Jayawardene et al., 2005). However, Odjugo (2010) argues that not any change in the climate should be considered as climate change since climate fluctuates and varies in monthly, seasonal, annual, decades, periodic, quasi-periodic or non-periodic time scales. And in his overview of climate change in Nigeria, he established that rainfall has decreased by $81 \mathrm{~mm}$ within 105 years period. Thus, not to mistake climate fluctuation for climate change, Ayoade (2003) recommended that a secular variation not up to $100-150$ years should not be regarded as climate change if the condition will quickly reverse later. 
The factors responsible for climate change are variations in solar intensity and green house gases alongside aerosols (Hansen and Lacis, 1999). Anthropogenic activities leading to increased green house gases have caused some natural processes to become chaotic and unpredictable. Such natural processes that have been affected by man induced increased green house gases particularly include global surface temperature and hydrological cycle (Trenberth, 1998). Although, no direct link between GHG and precipitation has been found yet Karl and Trenberth (2003) in a modeled climate system found that for extremely increasing temperature coupled with water holding capacity of the atmosphere, there is corresponding extreme increase in precipitation. This type of relationship whether of direct proportionality or inverse proportionality of air temperature increase occasioned by GHG with rainfall in modeled climate has also been established by other researchers. At times it has been inferred from the study of other atmospheric parameters like Sea Surface Temperature (SST) or by speculations in related researches (Cox et al., 2008; Haarsma et al., 2005; Fauchereau et al., 2003; Menon et al., 2002; Gong and Wang, 2000). Therefore, it can be argued that waiting for so long (100-150 years) as suggested by Ayoade (2003) in the face of continuous excessive GHG released into the atmosphere (USEPA, 2006) could be detrimental and too late to react thereafter if the predictions from models turn out true.

The sun has an 11 years cycle and changes it polarity at the end of the cycle and based on the reversibility of magnetic poles, one would say that the sun has a 22 years periodicity (Moussas et al., 2005). The solar cycle has being known to affect other processes in nature even the night and day, seasons and years are fallouts of the relationship between the sun and earth. So studies of atmospheric parameters that cover a period of 22 years would have witnessed at least one solar cycle influence and as such the period should be deemed okay for the short term. However, the 11 years cycle is not strictly an 11 years term but varies between the ranges of 10-12 years and as such other different solar cycles differing in years of the range of $\sim 87, \sim 210$ and $\sim 1,470$ years periodicities are known to exist (Braun et al., 2005). The solar cycle as it varies causes changes to other physical parameters like the solar wind (Scherer and Fahr, 2003; Lean et al., 2002). The cycle is also believed to be responsible for climate change. The 60,000 years long millennial scale climate changes found in Greenland ice cores and North Atlantic ocean cores has been attributed to variations in the solar cycles (Van Geel et al., 1999). Also still in Greenland, Ram et al. (1997) found the dust in ice-core dated to about
100,000 years BP to have a solar forcing cycle of 11 years. Increase in surface temperature has been found to coincide with increase in solar activity within a 400 years term (Hoyt and Schatten, 1993) and Lean et al. (1995) also attest to solar forcing on the surface temperature with particular regards to the Northern hemisphere. The heat energy of ocean is found to change along with an 11 years cycle (Wigley and Raper, 1990). The essence of this research is to find out the trend of rainfall in Abeokuta within a 22 years (1981-2002) period and the corresponding effect the sun has on it.

\section{MATERIALS AND METHODS}

The location under focus is Abeokuta $\left(7^{\circ} 15 \mathrm{~N}, 3^{\circ} 35^{\prime} \mathrm{E}\right)$ the capital city of Ogun state, Nigeria. The data used for this research were obtained from Nigerian Meteorological Services, NIMET office here in Abeokuta where the data are reportedly taken. The 22 years (1981-2002) rainfall data were biased into total amount of rainfall and total number of days of rainfall. To void the effect of serial correlation on the outcome of the test for trend, the correlation co-efficient $\mathrm{R}$ was examined and in cases whereby the correlation co-efficient was $\geq 0.30$ then the series was prewhitened using the method:

$$
Y_{t}=x_{t}-R_{1} x_{t-1}
$$

Examination of the possibility of existence of significance trend is by the Mann-Kendall rank correlation described below.

Mann-Kendall rank correlation; for a data set of $n$ size whereby $n$ is not $<10$, a mean of zero and a standard deviation of 1 also assuming that the time series is independent then the Mann-Kendall statistic $\mathrm{S}$ is described as:

$$
\begin{array}{rlrl}
\operatorname{sign}\left(\mathrm{x}_{\mathrm{j}}-\mathrm{x}_{\mathrm{i}}\right) & =1 & \text { if } \mathrm{x}_{\mathrm{j}}-\mathrm{x}_{\mathrm{i}}>0 \\
& =0 & \text { if } \mathrm{x}_{\mathrm{j}}-\mathrm{x}_{\mathrm{i}}=0 \\
& =-1 & \text { if } \mathrm{x}_{\mathrm{j}}-\mathrm{x}_{\mathrm{i}}<0 \\
\mathrm{~S} & =\sum_{\mathrm{i}=1}^{\mathrm{n}-1} \sum_{\mathrm{j}=\mathrm{i}+1}^{\mathrm{n}} \operatorname{sign}\left(\mathrm{x}_{\mathrm{j}}-\mathrm{x}_{\mathrm{i}}\right)
\end{array}
$$

Here, $x_{i}$ and $x_{j}$ are sequential data for the ith and $j$ th terms.

$$
\operatorname{VAR}(S)=\frac{n(n-1)(2 n+5)}{18}
$$

For situation where ties occur then $\operatorname{VAR}(\mathrm{S})$ is extended to the form: 


$$
\operatorname{VAR}(S)=\frac{\left[n(n-1)(2 n+5)-\sum_{p-1}^{q} t_{p}\left(t_{p}-1\right)(2 t+5)\right]}{18}
$$

Where:

$\mathrm{q}=$ The number of tied groups

$t_{p}=$ The number of data values in the pth group

$$
\begin{array}{rlr}
Z & =\frac{S-1}{\sqrt{\operatorname{VAR}(S)}} \text { if } S>0 \\
& =0 & \text { if } S=0 \\
& =\frac{S+1}{\sqrt{\operatorname{VAR}(s)}} & \text { if } S<0
\end{array}
$$

The null hypothesis Ho for a two sided test is rejected when

$$
|Z| \geq Z_{\alpha / 2}
$$

at $\alpha$ level of significance. If $Z$ is positive then the trend is increasing and if $Z$ is negative then the trend is decreasing.

The effect of seasonality on the outcome of trend analysis can be eliminated be performing the statistical analysis on either monthly data or on data that are divided into different seasons. The monthly data are also evaluated so that the outcome will not be in doubt of seasonal effect on the yearly data.

In an attempt to verify if year to year variability of the rainfall accumulated amount received in the location is directly influenced by solar intensity within the period under review, the yearly values averaged from daily values of reconstructed Total Solar Intensity (TSI) data downloaded from Max Planck Institute website were used to estimated the daily solar radiation for the horizontal plane in the absence of the atmosphere.

The global solar radiation on the horizontal plane Ho (in $\mathrm{MJ} \mathrm{m}^{-2}$ ) received at a particular location can be calculated (Iqbal, 1983; Duffie and Beckman, 1980) as follows:

$$
\begin{aligned}
\text { Ho } & =\frac{24 \times 3600}{\pi} \times \mathrm{TSI} \times \mathrm{E}_{\mathrm{o}} \times \\
& \left(\cos \phi \cos \delta \sin \mathrm{w}_{\mathrm{s}}+\frac{2 \pi \mathrm{w}_{\mathrm{s}}}{360} \sin \phi \sin \delta\right)
\end{aligned}
$$

Whereby TSI is the total solar irradiation at the mid distance between the sun and the earth otherwise known as the solar constant and the eccentric factor $\mathrm{E}_{0}$ is given as:

$$
\begin{gathered}
\mathrm{E}_{0}=1.000110+0.034221 \cos \Gamma+0.001280 \sin \\
\Gamma+0.000719 \cos 2 \Gamma+0.000077 \sin 2 \Gamma
\end{gathered}
$$

The day angle $\Gamma$ (in radiance) in the expression for the eccentric factor above is given as:

$$
\Gamma=2 \pi\left(\mathrm{d}_{\mathrm{n}}-1\right) / 365^{*}
$$

Furthermore other parameters found in the expression for Ho such as the declination angle $\delta$ and the hour angle $\mathrm{W}_{\mathrm{s}}$ can be given as:

And:

$$
\delta=23.45 \sin \left(\frac{360 \times\left(284+d_{\mathrm{n}}\right)}{365^{*}}\right)
$$

$$
\mathrm{w}_{\mathrm{s}}=\cos ^{-1}(-\tan \phi \tan \delta)
$$

Within the foregoing, $d_{n}$ is the day of the year and it's a maximum of 366 for leap years otherwise it is 365 while $\phi$ is the latitude of the location. The * value 366 instead of 365 was used for leap years.

\section{RESULTS}

Characterizing the rainfall from January to December, the pattern over the 22 years under review is such that starting from January when already the rainfall is low it increases gradually till it peaks in June. By July it descends quickly and goes to August break and then a swift rise to a second peak in September. The August break is a period when rainfall lessens considerably amidst the tick of the raining season and usually it occurs around the month of August every year in this part of the world. After the second peak is reached, there is another quick descend that goes to low level. The dry season stays from October and remain practically so through December, the last month of the year. This pattern is about the same for the total amount of rainfall and for its number of days (Fig. 1 and 2).

From the descriptive statistics (Table 1), the mean annual rainfall for the 22 years period is $1181.3 \mathrm{~mm}$ while the highest yearly rainfall amount is $1705.7 \mathrm{~mm}$. It rained for 2428 days out of about 8008 days, implying that

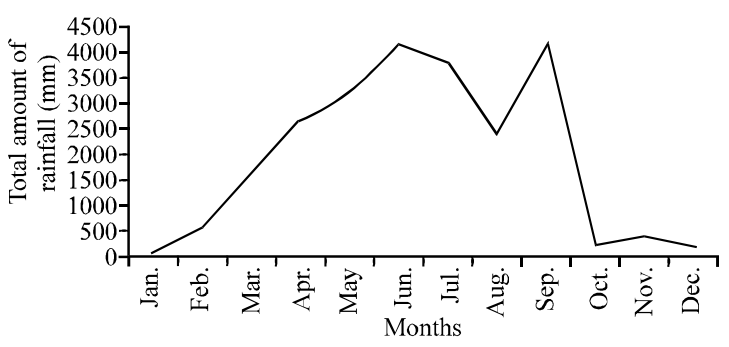

Fig. 1: Cummulative monthly variation of total amount of rainfall for 22 years of 1981-2002 in Abeokuta, Nigeria 
Res. J. Applied Sci., 6 (4): 264-271, 2011

Table 1: Result of descriptive statistics of the total amount of rainfall $(\mathrm{mm})$ and total number of rain days for Abeokuta from 1981-2002

\begin{tabular}{|c|c|c|c|c|c|c|c|}
\hline Parameters & Mean & SD & Median & Min. & Max. & Sum & Range \\
\hline Total amount of rainfall (mm) & 1181.3 & 254.2 & 1145.7 & 796.8 & 1705.7 & 25988.2 & 908.9 \\
\hline Days of rainfall & 110.4 & 15.3 & 110.5 & 75.0 & 136.0 & 2428.0 & 61.0 \\
\hline
\end{tabular}

Table 2: Non seasonal and seasonal results of the correlation coefficient and the Mann-Kendall Z test for rainfall in Abeokuta from 1981-2002

\begin{tabular}{|c|c|c|c|c|c|c|}
\hline \multirow[b]{2}{*}{ Parameters } & \multicolumn{2}{|c|}{ All seasons } & \multicolumn{2}{|c|}{ Dry season } & \multicolumn{2}{|c|}{ Raining season } \\
\hline & $\mathrm{R}$ & $\mathrm{Z}$ & $\mathrm{R}$ & $\mathrm{Z}$ & $\mathrm{R}$ & $\mathrm{Z}$ \\
\hline Total amount of rainfall (mm) & 0.20 & 0.90 & 0.15 & 0.56 & 0.12 & 0.39 \\
\hline Raining days & 0.29 & 1.47 & $0.31^{*}$ & 0.45 & 0.24 & 1.50 \\
\hline
\end{tabular}

*Prewhitening was applied

Table 3: The correlation co-efficient $\mathrm{R}$ and the Mann-Kendall Z-test for both total amount of rainfall $(\mathrm{mm})$ and total number of days of rain for the monthly periods of 1981-2002 in Abeokuta

\begin{tabular}{|c|c|c|c|c|}
\hline \multirow[b]{2}{*}{ Months } & \multicolumn{2}{|c|}{ Total amount of rainfall } & \multicolumn{2}{|c|}{ Rainy days } \\
\hline & $\mathrm{R}$ & $\mathrm{Z}$ & $\mathrm{R}$ & $\mathrm{Z}$ \\
\hline January & 0.03 & -0.01 & 0.11 & -0.34 \\
\hline February & 0.06 & -0.41 & 0.01 & -0.32 \\
\hline March & 0.00 & -0.06 & 0.03 & 0.14 \\
\hline April & 0.21 & 1.35 & 0.00 & -0.03 \\
\hline May & $0.33^{*}$ & -0.85 & 0.01 & 0.17 \\
\hline June & 0.18 & 0.00 & 0.03 & 0.00 \\
\hline July & 0.33 & 1.13 & $0.40^{*}$ & 1.02 \\
\hline August & 0.17 & 0.59 & $0.31 *$ & 0.82 \\
\hline September & 0.17 & 0.67 & 0.03 & 0.37 \\
\hline October & 0.28 & 1.24 & 0.26 & 1.34 \\
\hline November & 0.02 & -0.68 & 0.27 & 0.86 \\
\hline December & 0.03 & 0.32 & 0.02 & 0.37 \\
\hline
\end{tabular}

*Prewhitening was applied

the ratio of rain days to non-rain days is about 3:7. Within the period, the average of rainy days is about 110 days, though the number of rain days can be as low as 75 days and as high as 136 days.

The $Z_{\alpha / 2}$ (critical $Z$ ) values which can be read off from statistical table or evaluated as recommended in Obot et al. (2010) at $\alpha$ equal to $0.10,0.05$ and 0.01 levels of significance or 90,95 and $99 \%$ confidence levels are 1.64 , 1.96 and 2.58 , respectively. And from the results of Table 2, the absolute Mann-Kendall $\mathrm{Z}$ values for both the cumulative rainfall and rain days are 0.90 and 1.47 , respectively for non seasonal data. None of the absolute $\mathrm{Z}$ values is greater than any of the critical values at the confidence level considered here hence the null hypothesis that no significant trend occurred is accepted. To void the outcomes of any seasonal effect, the data were segmented into the two seasonal periods of dry season and raining season. The months that had their total rainfall amount lower than the mean rainfall fell into the dry season. These dry months include January, February, March, October, November and December. Whereas, the raining season months are April, May, June, July, August and September (Fig. 3). The two seasons were analyzed to see if there is any significant trend, again none existed (Table 2). Lastly the test was applied on

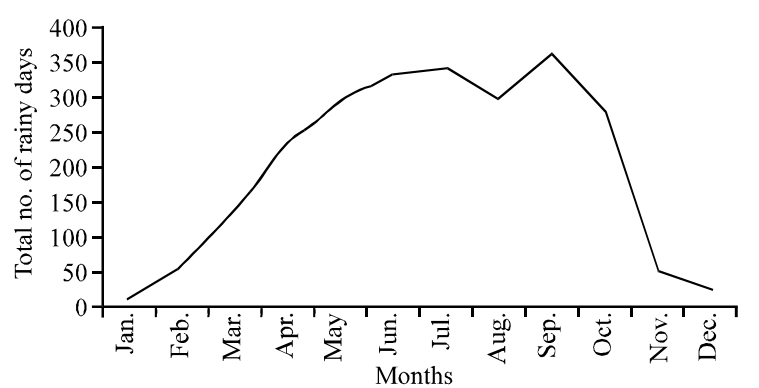

Fig. 2: Graph showing the cumulative monthly variation of rain days for 22 years of 1981-2002 in abeokutta, Nigeria

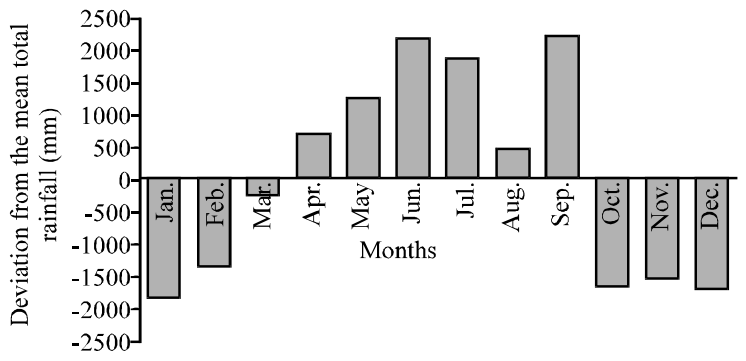

Fig. 3: Block chart of the accumulated monthly deviation of rainfall from the mean rainfall where upper blocks are raining seasons months and lower blocks are dry seasons months of the year, respectively

monthly basis whereby also no significant trend occurred (Table 3). Thus, there is no significant trend whatsoever throughout the 22 years considered.

However, June showed characteristically no positive or negative trend for the total amount of rainfall and rainy days. Both total amount and number of days of rainfall in January and February have negative insignificant trends while positive insignificant trends for both parameters exist in July, August, September, October and December. Conflicting positive and negative trends between total amount of rainfall and rainy days are found in 4 months namely March, April, May and November (Table 3). Year in year out rainfall occurrence relies on the sun-earth 


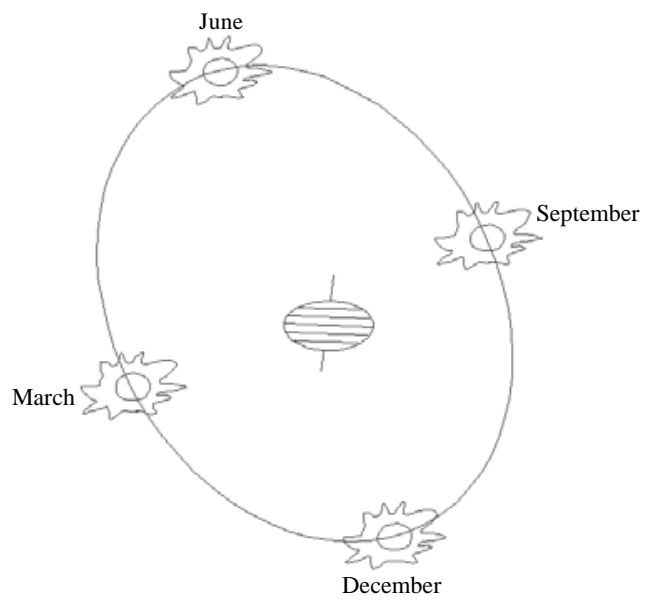

Fig. 4: Schematic diagram of the sun at different elliptical positions across the earth

positions which brings about the different seasons. Assuming that the earth is held fixed and the sun is moving around the earth in its orbit then the sun is facing the earth's equator in March and September, respectively (Fig. 4). Apparently from Fig. 3, the 2 months bring about the crossing over from dry season to raining season and from raining season to dry season, respectively. After March the raining season is in place and after September, the dry season is in place. Notably, March is the lowest of the dry season while September is the highest of the raining season. The disparity between the peculiarities of the 2 months is that whereas no other month is as low in dryness as March, June competes equally in high rainfall as September.

Starting from March (Autumnal equinox/spring) on a clockwise motion the sun goes into the Northern hemisphere, moving upward from the equator, it attains the highest position in the orbit in June Solstice (summer) before returning to the equatorial plane in September (Vernal equinox/fall) that phase is the raining season. Thereafter, the sun moves downward into the Southern path which is not as long as the initial path from September, to the peak at December Solstice (winter) and then moves up back to the equatorial plane in March.

During this second phase, the sun is much closer to the earth because the peak of this trajectory is lower than that of the Northern path and thus much sunshine is witnessed than the other time so the dry season is in place. It should be taken into cognizance that the explanations of seasonal occurrences given here hold mainly for regions in the equator where Nigeria is also situated.

The solar cycle (Fig. 5) starts from high phase in the beginning of the data, makes sort of a y shaped kind of descends to a low phase around 1985. It then rises

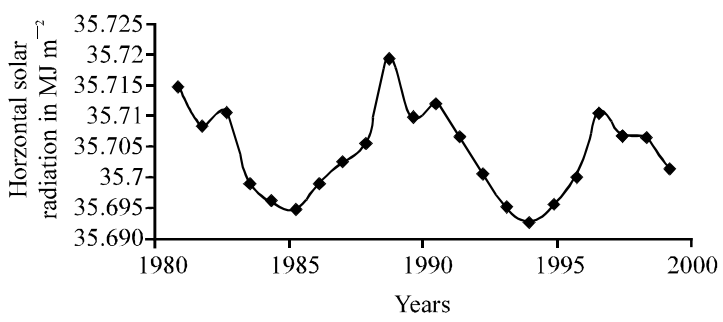

Fig. 5: Yearly plot of estimated horizontal global solar radiation at Abeokuta in the absence of the atmosphere

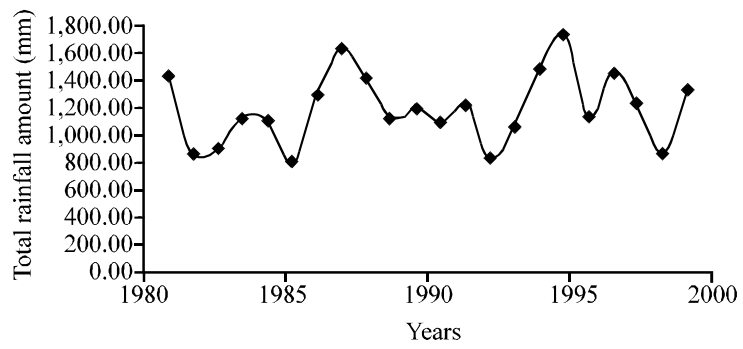

Fig. 6: Plot of yearly total rainfall amount of Aboekuta for the period 1981-2002

to a peak before repeating the format that was seen at the beginning of the data. Within 10 years time around 1995 , another such low stage of the type of around 1985 is attained. In contrast, the rainfall fluctuations hit four times low within this same period (Fig. 6).

\section{DISCUSSION}

With a cumulative monthly total amount of rainfall for 22 years getting as high as about $4,500 \mathrm{~mm}$ (Fig. 1), the location is one that experiences high amount of rain. Classifying the climate zones of Nigeria into three sections namely Sahel, Savanna and Guinea (Omotosho and Abiodun, 2007), Abeokuta the capital city of Ogun state is in the Southern part of Nigeria and it falls into the Guinea climate zone. The location is not too far away from the Atlantic ocean perhaps its closeness to the Atlantic ocean is the reason for the abundance of rain and definitely it can support plants and crops types that by nature survive in climates of high rainfall.

It seems that in recent times within Nigeria, most places witnessing significant trend in rainfall time series are areas in the Northern part that particular fall into the Sahel climate while those in the South and other Northern places outside the Sahel are having steady regime of rainfall. In other words insignificant changes in the trends of rainfall are wide spread in the South while the type of significant trend at the North is that of increasing trend 
(Ati et al., 2009; Obot et al., 2010). Abeokuta witnessed no significant trends in the evaluations carried out like other places in the same climatic zone as evidenced in the above cited works. A major factor that could be considered in trends evaluation is the type of method adapted by researches and another is the period that the studies portrayed. These two factors can bring about contradicting results sometimes even over the same location and caution must be taken when comparing works from different studies.

In Stevens and North (1996) research work investigating solar cycle forcing on the earth's surface temperature, one of the selected detected boxes is the region where Nigeria is situated; precisely the 10th out of 36 locations where the 11 years solar cycle influenced the historical temperature of both ocean and land. However, with regard to rainfall occurrence, the solar cycle or intensity has no direct effect on it as seen from the graphs of the yearly amount of rainfall (Fig. 6) and that of the solar radiation (Fig. 5). Both show that the solar intensity has little or no influence on the rainfall occurrence. The yearly rainfall availability and variability can probably be attributed to the West African monsoon which is yet to be fully understood. The monsoon which is a composite of some complex natural mechanisms such as the ocean land temperature and wind interactions and exchange, incidentally also has solar radiation as part of it (Abiodun et al., 2008; Omotosho et al., 2000; Le Barbe et al., 2002). Probably the Atlantic ocean forcing is predominating whereby relegating that of solar to the background (Lu and Delworth, 2005; Shanahan et al., 2009). Again, the complex nature of rainfall is probably the reason why the change in natural constituents of gasses (GHG) and climatic parameter (temperature) has not been directly found to influence its occurrence.

It is important to note that with respect to solar forcing on rainfall, this study may be regarded as inconclusive because for an ideal investigation the rainfall data should be lengthy say much $>100$ years since the sun cycle is an 11 years term. For the 22 years data of rainfall used in this research, it corresponds to only two solar cycles which would result to two data points when biased with the solar 11 years frame. Evidences of solar forcing on rainfall arising from slight variations in solar intensity resulting in either drought or flood have been found using long term data of about 3-9 thousand years ago in this Holocene era (Agnihotri et al., 2002; Hodell et al., 2001; Fleitmann et al., 2003). But with the paucity of data in this region in general and in this study in particular, the observed 2 cycles of about 10 years existing in Fig. 5 could not be associated with any change in the rainfall of Fig. 6. In the absence of long data, it is suggested that palaeo-sciences, satellite observations and atmospheric modeling be used to reconstruct it and further studies be carried out.

\section{CONCLUSION}

Since, all the period considered witnessed no significant trend coupled with the uniqueness of the month of June, a month of very high rainfall that showed no coherent trend what so ever, Abeokuta rainfall regime is stable and activities like farming and agricultural investments can effectively be carried out in accordance with the existing pattern of rainfall that is here characterized. The raining season is from April to September while the dry season is from October to March. However, continuous monitoring is advised because there can be a U-turn in trend as time passes by (Obot et al., 2010). Globally expect with multi decadal data of long past that were reconstructed, solar forcing on rainfall is not known to exist and despite the fact that corresponding solar forcing on temperature as well as hydrological cycle are known to occur with data of recent times yet it does not extend to rainfall as against expectations so more studies are needed to clearly account for the anomaly. Be that as it may in the location studied for two solar minimums that occurred there were four rainfall minimums.

\section{REFERENCES}

Abiodun, B.J., J.S. Pal, E.A. Afiesimama, W.J. Gutowski and A. Adedoyin, 2008. Simulation of West African monsoon using RegCM3 Part II: Impacts of deforestation and desertification. Theoretical Applied Climatol., 93: 245-261.

Adger, W.N., S. Huq, K. Brown, D. Conway and M. Hulme, 2003. Adaptation to climate change in the developing world. Progress Dev. Stud., 3: 179-195.

Agnihotri, R., K. Dutta, R. Bhushan and B.L.K. Somayajulu, 2002. Evidence for solar forcing on the Indian monsoon during the last millennium. Earth Planetary Sci. Lett., 198: 521-527.

Ati, O.F., C.J. Stigter, E.O. Iguisi and J.O. Afolayan, 2009. Profile of rainfall change and variability in the Northern Nigeria, 1953-2002. Res. J. Environ. Earth Sci., 1: 58-63.

Ayoade, J.O., 2003. Climate Change. Vantage Publishers, Ibadan.

Braun, C.M., S. Rahmstorf, A.M. Ganopolski, C. Kubatzki, K. Roth and B. Kromer, 2005. Possible solar origin of the 1,470-year glacial climate cycle demonstrated in a coupled model. Nature, 438: 209-211.

Cox, P.M., P.P. Harris, C. Huntingford, R.A. Betts and M. Collins et al., 2008. Increasing risk of Amazonian drought due to decreasing aerosol pollution. Nature, 453: 212-215. 
Duffie, J.A. and W.A. Beckman, 1980. Solar Engineering of Thermal Procecesses. John Wiley and Sons, Inc., Canada.

Fauchereau, N., S. Trzaska, M. Rouault and Y. Richard, 2003. Rainfall variability and changes in Southern Africa during the 20th century in the global warming context. Natural Hazards, 29: 139-154.

Fleitmann D., S.J. Burns, M. Mudelsee, U. Neff, J. Kramers, A. Mangini and A. Matter, 2003. Holocene forcing of the Indian monsoon recorded in a stalagmite from Southern Oman. Science, 300: 1737-1739.

Gong, D.Y. and S.W. Wang, 2000. Severe summer rainfall in China associated with enhanced global warming. Climate Res., 16: 51-59.

Goswami, B.N., V. Venugopal, D. Sengupa, M.S. Madhusoodanan and P.K. Xavier, 2006. Increasing trend of extreme rain events over India in a warming environment. Science, 314: 1442-1445.

Haarsma, R.J., F.M. Selten, S.L. Weber and M. Kliphuis, 2005. Sahel rainfall variability and response to greenhouse warming. Geophysical Res. Lett., 32: L17702-L17702.

Hansen, J.E. and A.A. Lacis, 1999. Sun and dust versus green house gases: An assessment of their relative roles in global climate change. Nature, 346: 713-719.

Hodell, D.A., M. Brenner, J.H. Curtis and T. Guilderson, 2001. Solar forcing of drought frequency in the Maya Lowlands. Science, 297: 1367-1370.

Hoyt, D.V. and K.H. Schatten, 1993. A discussion of plausible solar irradiance variation, 1700-1992. J. Geophysical Res., 99: 18895-18906.

Hunter, P.R., 2003. Climate change and waterborne and vector-borne disease. J. Applied Microbiol., 94: $37 \mathrm{~S}-46 \mathrm{~S}$.

Iqbal, M., 1983. An Introduction to Solar Radiation. Academic Press, New York, pp: 223.

Jayawardene, H.K.W.I., D.U.J. Sonnadara and D.R. Jayewardene, 2005. Trends of rainfall in sri lanka over the last century. Sri Lankan J. Physics, 6: 7-17.

Karl, T.R. and K.E. Trenberth, 2003. Modern global climate change. Science, 302: 1719-1723.

Omokhafe, O. and A. Emuedo, 2006. Evaluation of influence of five weather characters on latex yield in Hevea brasiliensis. Int. J. Agric. Res., 1: 234-239.

Laux, R., G. Jackel, R.M. Tingem andH. Kunstmann, 2010. Impact of climate change on agriculture productivity under rainfed conditions in Cameroon: A method to improve attainable crop yields by planting date adaptation. Agric. For. Meteorol., 150: 1256-1271.

Le Barbe, L., T. Lebel and D. Tapsoba, 2002. Rainfall variability in west Africa during the years 1950-1990. J. Climate, 15: 187-202.
Lean, J., J. Beer and R. Bradley, 1995. Reconstruction of solar irradiance since 1610: Implications for climate change. Geophys. Res. Lett., 22: 3195-3198.

Lean, J.L., Y.M. Wang and N.R. Jr. Sheeley, 2002. The effect of increasing solar activity on the Sun's total and open magnetic flux during multiple cycles: Implications for solar forcing of climate. Geophysical Res. Lett., 29: 2224-2224.

Lee, M.S., K. Nakane, T. Natatsubo, W.H. Mo and H. Koizumi, 2002. Effects of rainfall events on soil $\mathrm{CO}_{2}$ flux in a cool temperate deciduous broad-leaved forest. Ecol. Res., 17: 401-409.

Lu, J. and T.L. Delworth, 2005. Oceanic forcing of the late 20th century Sahel drought. Geophysical Res. Lett., 32: L22706-L22706.

Menon, S., J. Hansen, L. Nazarenko and Y. Luo, 2002. Climate effects of black carbon aerosols in China and India. Science, 297: 2250-2253.

Morduch, J., 1995. Income smoothing and consumption smoothing. J. Econ. Perspectives, 9: 103-114.

Moussas, X., J.M. Polygiannakis, P. Preka-Papadema and G. Exarhos, 2005. Solar cycles: A tutorial. Adv. Space Res., 35: 725-738.

Mudita, I.I., C. Chiduza, S. Richardson-Kageler and F.S. Murungu, 2008. Evaluation of different strategies of intercropping maize (Zea mays L.) and soya bean (Glycine $\max$ (L.) merrill) under small-holder production in sub-humid Zimbabwe. J. Agron., 7: $237-243$.

Obot, N. I., M.A.C. Chendo, S.O. Udo and I.O. Ewona, 2010. Evaluation of rainfall trends in Nigeria for 30 years (1978-2007). Int. J. Physical Sci., 5: 2217-2222.

Odjugo, P.A.O., 2010. General overview of climate change impacts in Nigeria. J. Human Ecol., 29: 47-55.

Omotosho, J.B. and B.J. Abiodun, 2007. A numerical study of moisture build-up and rainfall over West Africa. Meteorol. Appl., 14: 209-225.

Omotosho, J.B., A.A. Balogun and K. Ogunjobi, 2000. Predicting monthly and seasonal rainfall, onset and cessation of the rainy season in West Africa using only surface data. Int. J. Climatol., 20: 865-880.

Radford, A.N. and M.A. Du Plessis, 2003. The importance of rainfall to a cavity-nesting species. Ibis, 145: 692-694.

Ragab, R. and C. Prudhomme, 2002. Climate change and water resources management in Arid and Semi-Arid regions; prospective and challenges for the $21 \mathrm{st}$ century. Biosyst. Eng., 81: 3-34.

Ram, M., M. Stolz and G. Koenig, 1997. Eleven year cycle of duct concentration variability observed in the dust profile of the GISP2 ice core from Central Greenland: Possible solar cycle connection. Geophysical Res. Lett., 24: 2359-2362. 
Ronen, K. and D. Avinoam, 1999. Distribution of plants species in Israel in relation to spatial variation in rainfall. J. Vegetation Sci., 10: 421-432.

Sala, O.E. and W.K. Lauenroth, 1982. Small rainfall events: An ecological role in semi-arid regions. Oecol. (Berl), 53: 301-304.

Scherer, K. and H.J. Fahr, 2003. Solar cycle induced variations of the outer heliospheric structures. Geophysical Res. Lett., 30: 1045-1045.

Shanahan, T.M., J.T. Overpeck, K.J. Anchukaitis, J.W. Beck and J.E. Cole et al., 2009. Atlantic forcing of persistent drought in West Africa. Science, 324: 377-380.

Shukla, J., C. Nobre and P. Sellers, 1990. Amazon deforestation and climate change. Science, 247: 1322-1325.

Stevens, M.J. and G.R. North, 1996. Detection of the climate response to the solar cycle. J. Atmospheric Sci., 53: 2594-2607.
Tielborger, K. and R. Kadmon, 2000. Temporal environmental variation tips the balance between facilitation and interference in desert plants. Ecology, 81: 1544-1553.

Trenberth, K.E., 1998. Atmospheric moisture residence times and cycling: Implications for rainfall rates and climate change. Climatic Change, 39: 667-694.

USEPA, 2006. Global Anthropogeric Non- $\mathrm{CO}_{2}$ Greenhouse Gas Emission: 1990-2020. US EPA, Washington, DC.

Van Geel, B., O.M. Raspopov, H. Renssen, J. van der Plicht, V.A. Dergachev and H.A.J. Meijer, 1999. The role of solar forcing upon climate change. Q. Sci. Rev., 18: 331-338.

Wigley, T.M. and S.C.B. Raper, 1990. Climate change due to solar irradiance change. Geophysical Res. Lett., 17: $2169-2172$. 